\title{
Important change to Economic \& Labour Market Review
}

The September 2010 edition of Economic \& Labour Market Review (ELMR) will be the last to appear as a print publication. From October 2010, the journal will primarily be available as an online publication on the ONS website at www.statistics.gov.uk/elmr

The change will create new opportunities to develop and enhance the content and distribution of the publication while retaining its quality and values. ELMR will continue to contain in depth, peer reviewed topical articles analysing patterns and trends in the nation's economy and labour market using ONS data and describing related methodological developments.

ELMR's publisher Palgrave Macmillan will continue to provide on-demand printed copies to subscribers who prefer to receive the publication in that medium, as well as a value-added online subscription service to its content as part of their UK National Statistics Collection. More information on these services is available at www.palgrave.com/ons or email ons@palgrave.com

Feedback on any aspect of the new online publication would be greatly welcomed and should be sent to elmr@ons.gsi.gov.uk 